\title{
A comparative study of efficacy and safety of $5 \%$ topical minoxidil with platelet rich plasma versus platelet rich plasma as a monotherapy in male patients with androgenetic alopecia
}

\author{
Prashanth R. Kamath ${ }^{1, *}$, Saumya Goel², Ashok Menon ${ }^{3}$, Amita Murali Babu ${ }^{4}$, Hafsa Eram ${ }^{5}$ \\ ${ }^{1}$ Assistant Professor, ${ }^{2}$ Post Graduate, ${ }^{3}$ Senior Resident, ${ }^{\mathbf{4} 5}$ Post Graduate, Dept. of Dermatology, Venereology and Leprosy, A.J. \\ Institute of Medical Sciences and Research Centre, Kuntikana, Mangalore, Karnataka, India
}

*Corresponding Author:

Email: prashanthkamath@gmail.com

\begin{abstract}
Introduction: Male baldness is genetically determined, most common gradually progressive hair disorder leading to miniaturization of hair follicles. Various modalities have been used in various studies without significant results.

Objective: The aim was to study and compare the two modalities of treatment and to evaluate their results.

Materials and Methods: This is prospective, comparative study. Sample size was 40, twenty in each group. Group 1 was given $5 \%$ topical minoxidil solution two times in a day till six months and platelet rich plasma (PRP), Group 2 was given only PRP at three weekly interval for six months. Parameters evaluated before starting, after three months and after six months for - Hair pull test, anagen/telogen ratio, Patient's, Physician's assessment and clinical photographs.

Results: On evaluating group 1 showed relatively more significant improvement. On hair pull test significant reduction of hair breakage in group 1. Anagen/telogen ratio showed $8.9 \pm 0.3 \%$ improvement in anagen hair in group 1 while $5.9 \pm 0.5 \%$ was in group 2. Improvement was seen in patients of group 1 more than patients of group 2 based on patient's assessment and photographs.

Conclusion: $5 \%$ minoxidil when given with platelet rich plasma was superior and better when compared to platelet rich plasma alone.
\end{abstract}

Keywords: AGA, PRP, Minoxidil.

\section{Introduction}

Alopecia is a term used to determine loss of hair which results in diminution of hair ${ }^{1}$ over the vertex and frontal recession or patterned hair loss. ${ }^{2}$ Male baldness also known as androgenetic alopecia (AGA) is a very common condition which results in severe hair loss. ${ }^{3}$ It is a genetically determined non-scarring type of alopecia which is progressive in nature and is due to miniaturization of hair follicles. ${ }^{4,5}$

Although many treatments are available oral finasteride and topical minoxidil are FDA approved and requires use for a longer duration of time and are associated with various side effects like hypertrichosis but both of them doesn't restore hair completely. ${ }^{6}$

Minoxidil was developed originally for treatment of hypertension and is a vasodilator, acts over the potassium channels ${ }^{7}$ which acts over the arterioles through various mechanisms to reduce the peripheral resistance. ${ }^{8}$ It helps to lengthen the anagen phase, increases the size of hair follicle and shortens the period of hair cycle. ${ }^{9}$ Oral minoxidil was associated with certain side effects like weight gain due to retention of water but on further trials and investigation 5\% topical solution showed no side effects and was better than oral minoxidil. $^{7}$

Platelet rich plasma (PRP) is a product formed by the processing of autologous blood to produce concentration of platelets. This product is derived from the platelets after its activation which in turn releases alpha granules and is rich in multiple growth factors. ${ }^{10-12}$
These growth factors helps in inducing the proliferation of cells of dermal papilla. One of the factor namely Vascular endothelial growth factor results in improving the angiogenesis of anagen phase. ${ }^{13}$

Growth factors acts over the bulbar region of hair follicle binds with their receptors. Ectodermal cells lead to formation of epidermal cells and sebaceous glands in these bulge regions while germinative mesenchymal cells are seen within the dermal papilla. These cells along with various growth factors forms and helps in forming future follicular units by various interactions. ${ }^{14}$

PRP also helps to improve the regeneration of tissues, maintain hemostasis with the help of various growth factors which causes proliferation and cell differentiation. ${ }^{15}$

\section{Materials and Methods}

This is a prospective, comparative study which was done in A. J. Institute of Medical Sciences, Mangalore, Karnataka from Feb-July 2018. In this study, sample size was 40 , with twenty in each group. After obtaining the consent from the patients, Adult males diagnosed with androgenetic alopecia based on modified Norwood- Hamilton classification Grade II - VI, aged 18-45 years were included in this study. The approval was taken by the ethical committee.

Exclusion criteria were patient's unwilling for the procedure, patients with any other type of alopecia, patients on any anticoagulant medications, patients with history of any renal, hepatic disease, patients below 18 
years and above 45 years, female patients.

Complete history taking and detailed clinical examination was done in all the patients. Patients were explained everything about the study and procedure. Patients were put into two equal groups of twenty each. Patients in Group 1 were treated with both 5\% topical minoxidil and also platelet rich plasma. Group 2 patients were given only platelet rich plasma. All the necessary laboratory investigations were performed prior to the study. "Hair pull test was performed and the number of hairs extracted were counted. Trichogram was used to measure the ratio of anagen/ telogen in which 20 hairs were pulled out and removed from the parietal region of the scalp with help of forceps. These were mounted over a slide and examined under microscope for anagen and telogen hairs". ${ }^{16}$ Hairs with long rectangular shafts and dark pigmentation of bulbar region were considered as anagen phase hair follicles, while hairs with unpigmented bulb, short thick shaft were considered as telogen follicles.

Group 1: 5\% Topical minoxidil and platelet rich plasma

We asked Patients to apply 5\% topical minoxidil solution two times in a day till six months. Patients had to apply the solution all over their scalp and massage it gently into the skin. Patients were advised to keep the hairs dry for at least a period of 4 hours after application. Patients in this group were called for injections of PRP every three weeks for a total six months to give total of 6 sittings. Patients were assessed before starting the procedure, after three months and after six months of starting the treatment.

Group 2: Platelet rich plasma

Patients in this group were treated with only PRP at three weekly intervals for a period of six months such that total of 6 sittings were done. Patient in this group was not put on any other medications.

Preparation of PRP: ${ }^{17}$ The PRP was prepared by collecting blood of around $20 \mathrm{cc}$ in the vacutainers with sodium citrate as an anticoagulant under full aseptic precautions from the median cubital vein of the patient. These vacutainers were then allowed to undergo rotations in the centrifugation machine known as "soft spin" at the rate of 1500 revolutions per minute for 6 minutes. After the first spin, blood separated into three layers, namely bottom layer of RBC, topmost acellular plasma layer also known as poor plasma layer and the intermediate layer called as buffy coat. This buffy coat was separated using pipette into another plain test tube and was subjected for second spin or "hard spin" at 2500 revolutions per minute for 15 minutes. After this spin, the platelets (PRP) got settled down at the bottom of test tubes while the upper layer platelet poor plasma was thrown. Only the bottom layer which had platelets was loaded into the insulin syringes and kept."

Method of Application: We applied anaesthesia topically all over the patient's scalp and it was kept like this for around an hour after which we cleaned the scalp properly first with betadine and then with spirit. Now by using insulin syringe we gave multiple injections of PRP over the area with hair loss using "nappage technique (multiple injections in a linear pattern one $\mathrm{cm}$ apart)". All precautions were taken while injecting. This process was done every three weeks for the patients till six months.

Patients were evaluated based on $-\mathrm{A}$ ) Hair pull test B) Anagen/ telogen ratio based on standardised trichogram C) "Patient's assessment by using linear analogue scale" D) "Physician's assessment by using standard seven- point scale to check for the hair growth" (Table 1) after six months of starting and photographs taken before starting, after three months and after six months. The photographs of vertex, temporal, frontal region of the scalp was taken using cameras.

"Linear analogue scale of 1-10 was used for patient's assessment (1- no result, 10 - best results) in regards to the degree of hair-fall and hair growth."

\section{Statistical Analysis}

All data were analysed using SPSS, version 16.0 statistical package (SPSS Inc., Chicago, IL, USA). Student's t-test was used to test the significance difference in the results between the two groups. Chi square test was used where ever required. $\mathrm{P}$ value of less than 0.05 was considered significant.

\section{Observation and Results}

A) Hair Pull Test: Hair pull test was positive in all the forty patients before the start of the treatment. At the end of 6 months number of hair pulled became normal in group 1 but in group 2 few patients still showed breakage of hairs.

B) Anagen / Telogen Ratio Based on Standardised Trichogram: Trichogram were used at the start of treatment and after six months of starting the treatment to compare the rate of improvement in ratio between the anagen hair/telogen hair ratio between the two groups. On evaluation percentage of improvement in anagen hair among group 1 patients was $8.9 \pm 0.3 \%$ while in group 2 after treatment was observed to be 5.9 $\pm 0.5 \%$. The percentage of telogen hair decreased post treatment in both the group, such that in patients of group 1 it was $3.8 \pm 0.2 \%$. In the second group, there was decrease of $2.9 \pm 0.4 \%$ seen. The difference of improvement in anagen / telogen ratio between both the group, group 1 showed more improvement. (Table 1)

C) Patient's Assessment by using Linear Analogue Scale: After 6 months of treatment, patient's satisfaction in group 1 was 8 on a linear analogue scale of $1-10$ and $70 \%$ patients showed an improvement in terms of the number of hair, thickness of hair volume and quality of hair. While in second group the score was around 5 and $62 \%$ of the patients showed improvement in terms of hair volume, thickness, number and quality of hair. 
D) Physician's Assessment Score by using Standard Seven- Point Scale to check for Hair Growth:

" $-1=$ mild worsening, $-2=$ moderate, $-3=$ severe worsening, $0=$ no change.

$+1=$ mild improvement, $+2=$ moderate,$+3=$ excellent improvement".

According to the Physician's assessment no patients in both groups showed any worsening of the condition after the treatment. Statistically significant improvement using Chi-square test $(\mathrm{P}<0.05)$ was seen in patients with first group than that of in patients with group 2 when we checked the results at sixth month of treatment. (Table 2)
Photographs were taken before we started treatment, then in third months and again after six month of treatment with the help of cameras. Patients in group 1 (Fig. 1 to Fig. 2) had more hair growth than patients in second group. (Fig. 3 to Fig. 4)

Side Effects: Patients complained of pain, pinpoint bleeding during the injections of platelet rich plasma. 6 of the patients complained of headache post procedure which was short lasting. No serious side effects were noticed. None of the patients complained of any erythema, irritation, active infections, or hair fall post procedure.

Table 1: To compare anagen / telogen ratio in both groups before and after 6 sessions

\begin{tabular}{|l|c|c|c|c|}
\hline \multirow{2}{*}{} & \multicolumn{2}{|c|}{ Group 1 } & \multicolumn{2}{c|}{ Group 2 } \\
\cline { 2 - 5 } & Before & After 6 sessions & Before & After 6 sesions \\
\hline Increase in anagen hairs (in \%) & $49 \pm 8$ & $58 \pm 2 \%$ & $51 \pm 3$ & $57 \pm 6 \%$ \\
\hline Decrease in telogen hairs (in \%) & $22 \pm 3$ & $18 \pm 5 \%$ & $26 \pm 2$ & $23 \pm 3 \%$ \\
\hline
\end{tabular}

Table 2: Comparison of physician's assessment between 2 groups at the end of 6 months. ${ }^{23}$

\begin{tabular}{|l|c|c|}
\hline \multicolumn{1}{|c|}{ Physician's assessment at 6 months } & $\begin{array}{c}\text { Group 1 } \\
(\mathbf{N = 2 0})(\boldsymbol{\%})\end{array}$ & $\begin{array}{c}\text { Group 2 } \\
(\mathbf{N = 2 0})(\boldsymbol{\%})\end{array}$ \\
\hline No change & $0(0)$ & $1(5)$ \\
\hline Mild improvement & $3(15)$ & $7(35)$ \\
\hline Moderate improvement & $15(75)$ & $11(55)$ \\
\hline Excellent improvement & $2(10)$ & $1(5)$ \\
\hline
\end{tabular}

\section{Group 1 Patient 1}

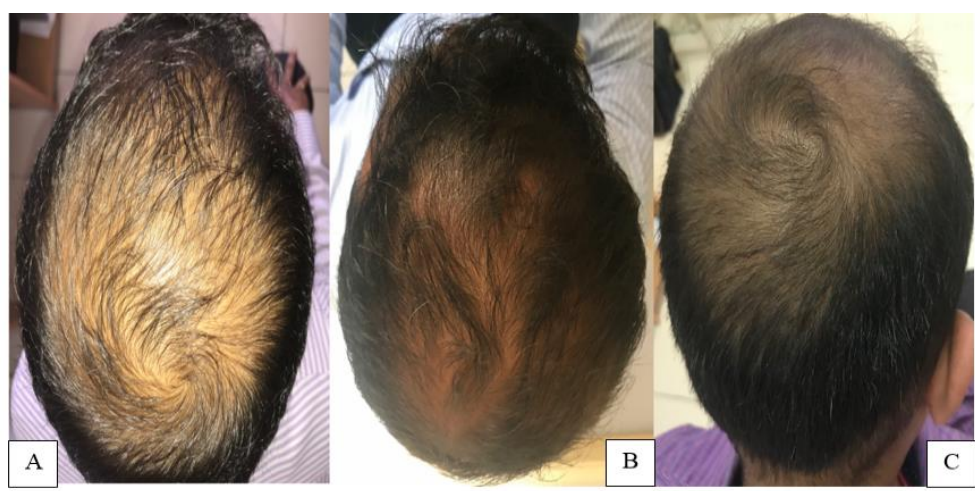

Fig. 1 A): Before treatment; B) After 3 months; C): After 6 months

\section{Group 1 Patient 2}

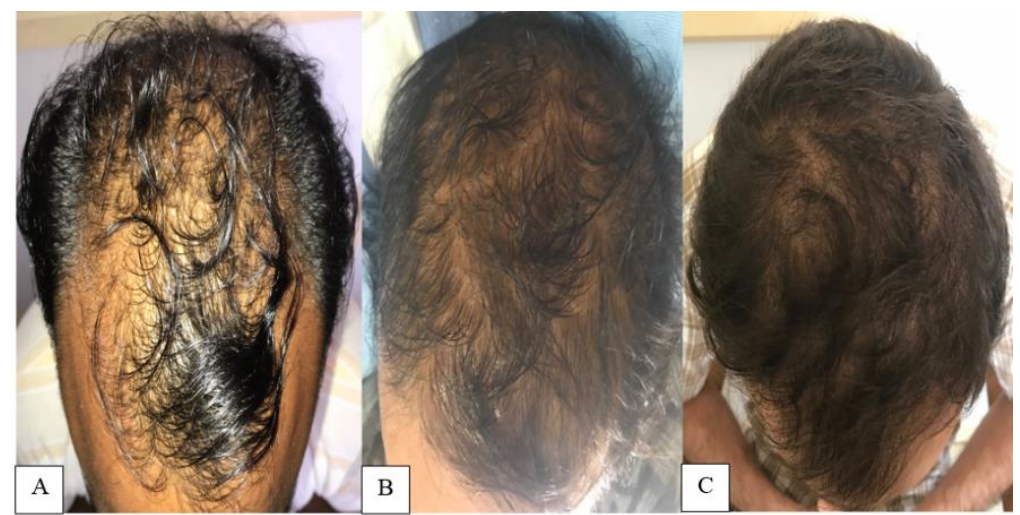

Fig. 2 A): Before treatment; B) After 3 months; C): After 6 months 


\section{Group 2 Patient 1}

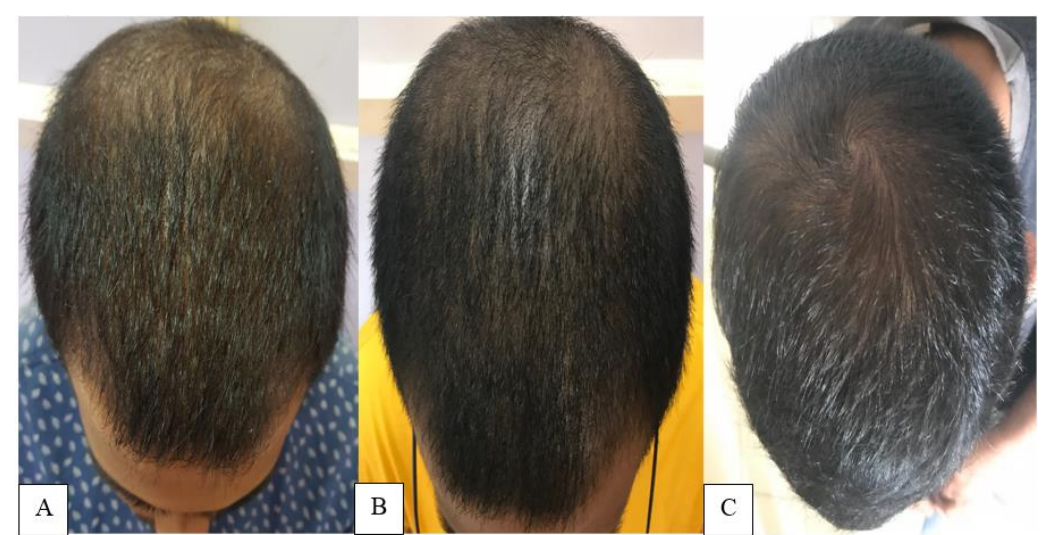

Fig. 3 A): Before treatment; B) After 3 months; C): After 6 months

\section{Group 2 Patient 2}
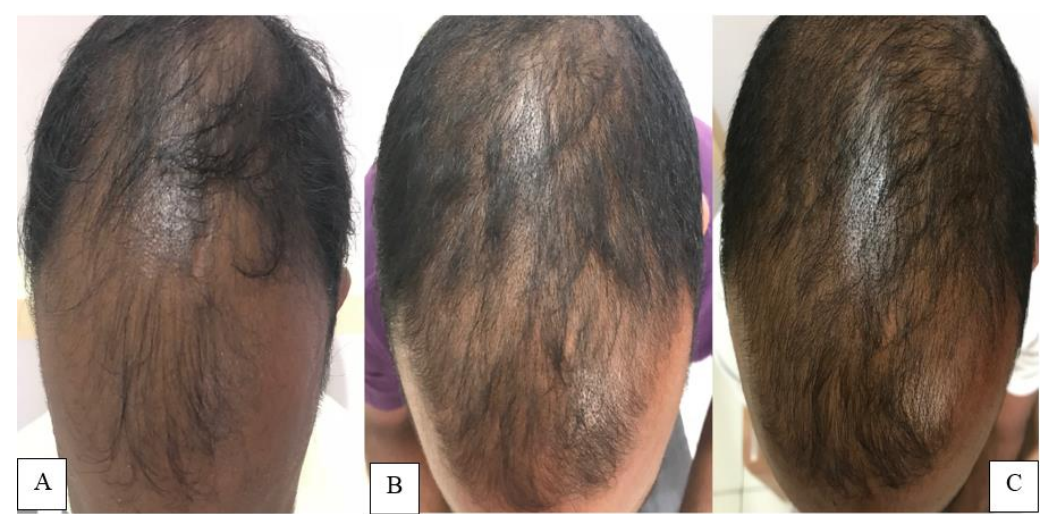

Fig. 4 A): Before treatment; B) After 3 months; C): After 6 months

\section{Discussion}

Androgenetic alopecia (AGA) affects large number of men and women worldwide usually starts around puberty and progresses eventually to involve patients below 40 years of age group. ${ }^{18}$ Although the condition is not a serious disorder but patients presents with loss of well-being, self-esteem and is associated with psychological and mental stress. One of the studies reported by Wells et al. stated loss of self-esteem, depression, neuroticism in patients. ${ }^{19}$

It is a hereditary, multifactorial disorder mostly associated with low levels of androgenic hormone dehydroepiandrosterone (DHEAS). This condition is associated with transformation of terminal hair into vellus hair gradually which leads to shortening of hair follicles and affects the phases of hair cycle. ${ }^{20}$ Minoxidil is a drug which is approved by US FDA for hair loss. The main action of this drug is to act over hair cycle by prolonging the phase of anagen and it also improves the number of hair follicles and acts over the dermal papilla to improve its proliferation and differentiation. ${ }^{13,21}$ Minoxidil also helps in improving the circulation of cutaneous blood flow.

According to study done by Ubel et al. ${ }^{14}$ after treatment with PRP the number of follicular units increased by $15.1 \%$ and there was improvement in hair density. PRP helps to improve the angiogenesis by expressing various vascular endothelial growth factors and helps in prolonging the anagen phase by its action over and around the hair follicle. ${ }^{22}$ In this study $70 \%$, $60 \%$ patients respectively in both groups had improvement in the hair volume, density and number after 6 months of treatment according to patient's assessment.

On physician's assessment, moderate improvement was present in $75 \%$ of patients in group 1 as compared to another group. In our study, no significant side effects were noticed in our patients.

Therefore, as per our study, patients treated with 5\% topical minoxidil and platelet rich plasma showed relatively more improvement according to physicians and patients assessment scale and even based on clinical photographs as compared to patients treated with monotherapy of platelet rich plasma.

\section{Conclusion}

Platelet rich plasma is a promising, new modality to treat hair loss as it acts by increasing the platelet concentration by various growth factors. Minoxidil has been in use from number of decades but is associated with few side effects. Both when used in combination proved to be more significantly efficacious and is 
associated with less side effects as compared to monotherapy of platelet rich plasma.

Funding: No funding sources.

Conflict of Interest: None.

\section{References}

1. Cotsarelis G, Miller SE. Towards a molecular understanding of hair loss and its treatment. Trends $\mathrm{Mol}$ Med. 2001;7:293-94.

2. Olsen EA, Dunlap FE, Funicella T, Koperski JA, Swinehart JM, Tschen E, et al. A randomized clinical trial of $5 \%$ topical minoxidil versus $2 \%$ topical minoxidil and placebo in treatment of androgenetic alopecia in men. $J$ Am Acad Dermatol. 2002;47:377-85.

3. Piraccini BM, Alessandrini A: Androgenetic alopecia. $G$ Ital Dermatol Venereol. 2014;149:15-24.

4. Blumeyer A, Tosti A, Messenger A, Reygagne P, Marmol V, Splus PI, Finner A, Kiesewetter F, Trueb R, Rzany B, Peytavi UB. Evidence Based (S3) Guidelines for the Treatment of Androgenetic Alopecia in Women and in Men. 2007:1-12.

5. Kaliyadan F, Nambiar A, Vijayaraghavan S. Androgenetic Alopecia: An update. Indian J Dermatol Venereol Leprol. 2013;79:613-25.

6. Blumeyer A, Tosti A, Messenger A, Reygagne P, Del Marmol V, Spuls PI, et al.; European Dermatology Forum (EDF). Evidence-based (S3) guideline for the treatment of androgenetic alopecia in women and in men. J Dtsch Dermatol Ges. 2011;9(Suppl 6):S1-57.

7. Rogers NE, Avram MR. Medical treatment for male and female pattern hair loss. J Am Acad Dermatol. 2008;54752.

8. Campese VM: Minoxidil: A review of its pharmacological properties and therapeutic use. Drugs. 1981;22:257-278.

9. Am J Clin Dermatol. 2007;8(5):285-90.

10. Lieberman J, Daluiski A, Einhorn TA. The Role of Growth Factors in the Repair of Bone. Biology and Clinical Applications. Investigation performed at the Department of Orthopaedic Surgery, University of California at Los Angeles Medical Center, Los Angeles, California, and the Department of Orthopaedic Surgery, Boston University Medical Center, Boston, Massachuset. J Bone Joint Surg Am. 2002;84(6):1032-44.

11. Landesberg R, Roy M. Glickman RS. Quantification of Growth Factor Levels Using a Simplified Method of Platelet-Rich Plasma Gel Preparation. J Oral Maxillofac Surg. 2000;58(3):297-300.

12. Sierra ALP, Aranegui RO, Ares MM, Martínez JLQ, González JMM. Quantiication of growth factors by using a new system for obtaining platelet-rich plasma. Med Oral Patol Oral Cir Bucal. 2011;16(4): 614-8.

13. Semalty M, Semalty A, Joshi GP, Rawat MS (2011) Hair growth and rejuvenation: An overview. J Dermatolog Treat. 22:123-132.

14. Uebel CO, da Silva JB, Cantarelli D, Martins P. The role of platelet plasma growth factors in male pattern baldness surgery. Plast Reconstr Surg. 2006;118:1458-67.

15. Pontual MAB, Magini RS. Plasma Rico em Plaquetas PRP e Fatores de Crescimento das Pesquisas Científicas à Clínica Odontológica. São Paulo: Ed.Santos;2004. p.16387.

16. J Cutan Aesthet Surg. 2014;7(2):107-110. doi: 10.4103/0974-2077.138352
17. Norwood OT. Male pattern baldness: Classification and incidence. South Med J. 1975;68:1359-65.

18. Wells PA, Willmoth T, Russell RJ. Does fortune favour the bald? Psychological correlates of hair loss in males. Br J Psychol. 1995;86:337-44.

19. Blumeyer A, Tosti A, Messenger A, Reygagne P, Del Marmol V, Spuls PI, et al. European Dermatology Forum (EDF).Evidence-based (S3) guideline for the treatment of androgenetic alopecia in women and in men. $J$ Dtsch Dermatol Ges. 2011;9(Suppl 6):S1-57.

20. Han JH, Kwon OS, Chung JH, Cho KH, Eun HC, Kim $\mathrm{KH}$. Effect of minoxidil on proliferation and apoptosis in dermal papilla cells of human hair follicle. J Dermatol Sci. 2004;34:91-8.

21. De Villez RL. Topical minoxidil therapy in hereditary androgenetic alopecia. Arch Dermatol. 1985;121:197202.

22. Hajheydari Z, Akbari J, Saeedi M, Shokoohi L. Comparing the therapeutic effects of finasteride gel and tablet in treatment of the androgenetic alopecia. Indian $J$ Dermatol Venereol Leprol. 2009;75:47-51.

23. Krupa Shankar D, Chakravarthi M, Shilpakar R. Male androgenetic alopecia: Population-based study in 1,005 subjects. Int J Trichology. 2009;1:131-3.

24. Besti EE, Germain E, Kalbermatten DF, Tremp M, Emmenegger V. Platelet-rich plasma injection is effective and safe for the treatment of alopecia. Eur J Plast Surg. 2013;36:407-12.

25. Blumeyer A, Tosti A, Messenger A, Reygagne P, Del Marmol V, Spuls PI, Trakatelli M, Finner A,

Kiesewetter F, Trueb R, Rzany B, Blume-Peytavi U, European Dermatology F (2011) Evidence-based (S3) guideline for the treatment of androgenetic alopecia in women and in men. J Dtsch Dermatol Ges 9 Suppl. 6(s6):S1-S57.

26. Greco J, Brandt R. The effects of autologous platelet rich plasma and various growth factors on non-transplanted miniaturized hair. Hair Transpl Forum Int. 2009;19:4950 .

27. Lopez V, Vaya A, Bautista D, Ricart JM. Autologous platelet-rich plasma as a potential therapeutic tool in androgenetic alopecia. $J$ Am Acad Dermatol. 2013;68:SAB103.

28. Tsuboi R, Tanaka T, Nishikawa T, Ueki R, Yamada H, Katsuoka K, et al. A randomized, placebo-controlled trial of $1 \%$ topical minoxidil solution in the treatment of androgenetic alopecia in Japanese women. Eur J Dermatol. 2007;17:37-44.

How to cite this article: Kamath PR, Goel S, Menon A, Babu AM, Eram H. A comparative study of efficacy and safety of $5 \%$ topical minoxidil with platelet richplasma versus platelet rich plasma as a monotherapy inmale patients with androgenetic alopecia. Ind J Clin Exp Dermatol. 2018;4(3):241-245. 